\title{
As sete meninas: reflexões sobre mulheres, experiência e efeitos jarawara*
}

Fabiana Maizza**

\section{Resumo}

A partir de minha etnografia com os Jarawara, povo falante de uma língua Arawá e habitante do médio curso do rio Purus, este artigo visa refletir sobre a festa de saída das meninas em reclusão, o mariná, e seus efeitos na composição de uma agente "levável". A ideia aqui desenvolvida é que a "sonolência" (nokobisa), o "cansaço" (mama) e a "beleza" (amosa) são formas de ações rituais que visam extrair dos corpos das mulheres suas capacidades de serem "leváveis" (towakama), de "serem carregáveis" (weyena). Essas qualidades estariam igualmente associadas aos xamãs que, após o consumo de rapé, são carregados nas costas de seus filhos-planta e experimentam relações com diversos tipos de seres no neme (a "camada superior") - seres que também encontram em seus sonhos. Procurarei assim pensar como uma certa noção de agência das mulheres jarawara pode estar vinculada à atividade onírica $e$ ao conhecimento xamânico.

Palavras-chave: Mulheres Indígenas, Etnografia, Teoria de Gênero, Agência, Ritual.

\footnotetext{
Recebido para publicação em 23 de março de 2016, aceito em 3 de novembro de 2016.

** Pós-doutoranda em Antropologia Social na Universidade de São Paulo, com bolsa Fapesp, São Paulo, SP, Brasil; e pós-doutoranda associada ao Centre Enseignement et Recherche en Ethnologie Amérindienne, EREA, Paris. fabianamaizza@gmail.com
} 
The Seven Girls:

Thoughts on Jarawara Women, Experience and Effects

\begin{abstract}
Based on my ethnography with the Jarawara, an Arawá speaking people of the Middle Purus river, the article aims to think about the girls' end of reclusion party, the mariná, and its effects on the composition of a "takeable" agent. The idea developed here is that the "somnolence" (nokobisa), the "tiredness" (mama) and the "beauty" (amosa) are forms of ritual actions that aim to draw out of the women's bodies their capacities of "being takeable" (towakama), of "being carriable" (weyena). Those qualities would also be associated with the shamans, that after consuming rapé (a tobacco based powder) are carried on the back of their plantchildren and experience relations with a variety of beings in the neme (the "upper layer") - beings which they meet in their dreams as well. I will try to think how a certain notion of jarawara women agency may be linked to the oneiric activity and to the shaman's knowledge.
\end{abstract}

Keywords: Amerindian Women, Ethnography, Gender Theories, Agency, Ritual. 
Em minha última estadia em Casa Nova, a maior aldeia do povo Jarawara, houve um grande campeonato de futebol, onde foram convidados muitos conhecidos ${ }^{1}$, sobretudo pessoas que moram nas proximidades, que se deslocaram para participar do campeonato. $\mathrm{O}$ prêmio para o time vencedor era um porco que havia sido criado para a ocasião. Após o dia de torneio, foi oferecido jantar para os participantes e por volta das $21 \mathrm{~h}$ começou um baile de forró, em que os anfitriões jovens e seus amigos cantavam tocando no teclado sucessos do estilo musical "arrocha" e "brega". A "pista" de dança permaneceu cheia a noite toda e a madrugada foi movimentada nos arredores das casas, com um vai $e$ vem constante de pessoas que bebiam, conversavam $e$ se deslocavam por diferentes motivos. Foi, sem dúvidas, uma grande festa, tanto em termos de quantidade de gente convidada, como em termos de diversão, conforme as pessoas jovens me descreveram a ocasião.

Por volta das três horas da manhã, eu já estava bastante cansada, mas permaneci perto da "pista", observando os/as jovens dançarem. Olhei a minha volta e percebi então que praticamente todas as mulheres com mais idade, convidadas $e$ anfitriãs, também estavam lá, como eu, sentadas, olhando o baile. Pensei que elas ainda estavam acordadas devido a uma "vontade" de ver o forró até o fim, como se nada pudessem perder daquela noite animada em meio a tantas noites calmas de seus cotidianos. Foi apenas no dia seguinte, ao conversar com algumas pessoas sobre os acontecimentos e fofocas da festa, que percebi que aquelas senhoras permaneceram acordadas até o amanhecer para "olharem", "cuidarem" (kakatoma) de suas

\footnotetext{
1 As pessoas que se autoidentificam como Jarawara vivem nas proximidades do médio curso do rio Purus, no Estado do Amazonas, e falam a língua jarawara (da família linguística Arawá), formando uma sociedade com aproximadamente 300 pessoas. Comecei meu diálogo com elas em 2004, e desde então tenho procurado retornar com regularidade para visitá-las. As minhas últimas idas à Casa Nova, no âmbito de meu pós-doutorado, foram financiadas pela Fapesp (Fundação de Amparo à pesquisa do Estado de São Paulo), órgão ao qual aqui agradeço.
} 
"filhas", "sobrinhas" ou "netas" Havia muitos homens não indígenas na aldeia, e as mulheres (mas também os homens) temem muito que "os brancos" (yara) "carreguem" (weye), "segurem" (bokori), "levem" (towaka) as jovens moças jarawara para os arredores da aldeia para ter relações sexuais com elas. Ou, pior ainda, que eles as "roubem" (boti) para se casarem com elas. Nessa noite de forró, algumas meninas foram "levadas" para o mato, apesar de seus parentes próximos as terem prevenido para "não irem com os homens". No entanto, elas não "obedeceram" (tokataba).

Pareceu-me que a presença atentiva de uma mulher mais velha faria com que essas moças não fossem "carregadas", como se essas senhoras "segurassem" (tamana) as meninas através de seus olhares - ainda que, como vimos, nem todas as meninas obedeçam. Por outro lado, existiria - e essa é a hipótese que eu quero explorar aqui - uma certa habilidade nessas jovens de serem "leváveis" (towakama), "carregáveis" (weyena), e por isso a vigilância exercida pelas mulheres mais velhas. Essa habilidade seria revelada às meninas no período que segue suas primeiras menstruações, quando elas ficam reclusas em compartimentos feitos especialmente para elas, os wawasa; e seria o efeito desejado da festa de saída mariná, algo que poderíamos qualificar como um ritual de iniciação feminina. Durante essas festas, o sono e o sonho seriam formas de aprendizado e conhecimento sobre as capacidades do corpo e da alma. Esses são os argumentos centrais que gostaria de tecer no decorrer deste artigo. Eles estão imbricados com a tentativa de tradução dos termos na língua jarawara: "weye" e "towaka". "Weye" seria algo como carregar, colocar/levar/carregar nas costas, usar (vestir) algo. Enquanto "towaka" remeteria aos atos de levar, de ser levado, de levar junto. O próprio vocabulário em que a festa é formulada mobiliza termos que dialogam com os primeiros: o pai "prende" (nawata) sua filha para depois "soltá-la" (sobana) no momento da festa. E o casamento também é concebido como uma maneira de "segurar": "se quiser casar, tem que segurar", me foi dito. A conjugalidade 
seria como um "segurar" (tamana) para não mais "soltar" (sobana).

A ideia que proponho é que na sociedade jarawara a agência feminina estaria vinculada aos termos towaka e weye e passaria pelo fato de as mulheres incorporarem/personificarem qualidades de "serem leváveis", de adquirem conhecimento através de viagens oníricas, efeito do mariná. Do ponto de vista de uma pessoa de tradição ocidental ${ }^{2}$, essas qualidades que eu adjetivo como agência poderiam ser vistas como "passivas" ou antíteses daquilo que o conceito de agente significaria para nós (Mahmood, 2001:210-212). No entanto, no mundo ameríndio, o sonhar é uma importante forma de aprendizado (Kopenawa; Albert, 2010). O que está subjacente a meu argumento é que a categoria mulher não deve ser dada a priori - a partir de nossos pressupostos que a "natureza" é dada e diferencia os sexos de forma inata (Strathern, 1980:191), mas sim entendida a partir das narrativas etnográficas. Assim, abriremos espaços para análises de sexo e gênero que levam em conta, ou tomam como ponto de partida, a diferença. ${ }^{3}$

2 Utilizo o termo Ocidental para me referir às sociedades que se encaixariam ao que Bruno Latour (2001) chamou de "modernos". Isto é, aquelas sociedades que se descrevem como diferentes das outras por "dominarem a natureza" através da ciência.

3 Não terei oportunidade de entrar nessa discussão aqui, mas um dos argumentos do movimento que ficou conhecido sob o nome de "terceira onda do feminismo" é que a possibilidade de diferença que as mulheres 'brancas' (da chamada "segunda onda do feminismo") conseguiam conceber até outras mulheres terem voz no discurso feminista, era uma diferença que não ousava questionar a fundação de suas próprias existências e fazeres (Trinh, 1987:14). O que o feminismo radical de mulheres 'não brancas' trouxe foi a desestabilização dos cânones do feminismo ocidental (Haraway, 2004:241). A diferença entre as experiências das mulheres se torna então a base na qual se constitui "a teoria feminista multi-cultural" (Haraway, 2004:227). Uma diferença corporificada, que parte das experiências vividas, personificadas, incorporadas. Emerge uma politica da diferença (Haraway, 2004:244), na qual o que está em pauta não é o relativismo, as diversas formas de 'se tornar mulher', mas sim uma reconstrução de conceitos de subjetividade social e as práticas de escrita a ela associada (Haraway, 2004:244). Sobre feminismos e diferença, ver também: Angela Davis 
Muito do que apresento neste trabalho está ligado à minha própria experiência em um mariná que aconteceu em maio de 2014: a festa de Dyimamirira. A mãe de Dyimamirira e também suas irmãs são as mulheres mais próximas de mim desde minha primeira ida à Casa Nova, em 2004. Quando cheguei para a festa de sua filha, Makeni me disse para amarrar minha rede no interior de sua casa, e fiquei assim a poucos metros do wawasa, a "casinha de reclusão", de Dyimamirira - sobre a qual falarei em detalhes mais adiante. Por conta dessa proximidade, vivenciei o mariná de uma forma muito particular. Poderia dizer que exponho aqui alguns de meus "deslumbres" (Strathern, 2014) naquela ocasião.

\section{Fertilidade?}

Dentre as ideias com as quais procuro dialogar neste trabalho, talvez a principal seja a ideia de que para o pensamento ocidental, a "natureza" é dada e inerentemente diferenciadora (Strathern, 1980:191). Por isso, localizamos as diferenças entre os sexos na "natureza" e elas seriam de ordem biológica (Strathern, 1980:191). Descrevemos as diferenças estabelecidas na vida social entre homem e mulher como se elas fossem originárias na biologia (Moore, 1994:813); pressupomos que "masculino" e "feminino" são duas categorias naturais de seres humanos, cujas relações são, em todos os lugares, estruturadas por suas diferenças biológicas (Collier; Yanagisako, 1987:7).

As discussões contemporâneas sobre gênero apontam, no entanto, para um posicionamento crítico, no qual não pode haver um significado unitário ou essencial atribuído à categoria "mulher" e à categoria "homem" (Moore, 1994:814). Esse posicionamento é também decorrente das controvérsias, ocorridas sobretudo na década de 1970, que questionavam a ideia, em plena expansão, da submissão universal da mulher. A objeção de mulheres

(2016), Audre Lorde (2015), Chandra Mohanty (1984), Avtar Brah (2006), entre outras. 
homossexuais, afro-americanas, "do terceiro mundo", e outras, mostrara que suas experiências como mulheres eram completamente diferentes daquelas de mulheres brancas, de classe média, heterossexuais que formulavam então as diretrizes da antropologia feminista. As críticas apontavam para a não inocência da categoria "mulher" (Haraway, 1985), para a natureza parcial de qualquer posição feminista (Strathern, 2004:35).

Foram apresentados diversos problemas à ideia da subordinação universal feminina, mas para os fins analíticos a que me proponho aqui gostaria de me deter sob dois. O primeiro é considerar que "mulher" é uma categoria natural dada pelo corpo, e de pressupor que "a biologia dita que as mulheres vão ser mães" (Rosaldo, 1974:23). Segundo essa lógica, existiria uma unidade doméstica, a família biológica que deveria reproduzir os membros da sociedade, oposta a uma entidade pública, a rede de alianças, equivalente à sociedade. A esse argumento se sobrepõe um segundo: o pressuposto de que existe uma transformação da natureza em cultura, e que ela deve ser repetida para que as sociedades se perpetuem através de suas regras culturais (LéviStrauss apud MacCormack, 1980:2). A proibição universal do incesto, $e$, sua aliada, a regra do casamento exogâmico - em suma, a teoria da aliança levistraussiana asseguraria dois tipos de dominação: a dominação do biológico pelo social, e da natureza pela cultura (Lévi-Strauss apud MacCormack, 1980:2). O que resulta na seguinte equação: a esfera doméstica cumpre as exigências biológicas da sociedade e a esfera publica é responsável pelas mudanças históricas nos sistemas econômico, políticos $e$ ideológicos (Collier; Yanagisako 1987:4). Nem é preciso dizer que as mulheres foram ditas estar destinadas à primeira, e os homens à segunda.

Como comentam Collier e Yanagisako (1987:5), a teoria da aliança pressupõe que em todos os lugares do mundo as mulheres seriam fornecedoras de serviços sexuais e domésticos, e por isso possuiriam um valor igual $e$ inerente, $e$ que os homens teriam a autoridade legítima de trocar mulheres. Encontramos aqui o pressuposto de "propriedade", "uma ramificação da metáfora da 
mercadoria" (Strathern 1988:134, tradução livre), que domina o pensamento ocidental. Na teoria da aliança, o valor das mulheres seriam suas capacidades de reprodução (Collier; Yanagisako 1987:5). Em outros termos, as mulheres possuiriam corpos reprodutores, dos quais os homens deveriam se apropriar (para a troca, e para a reprodução).

Por isso, nessa leitura, parece lógico que outras sociedades estejam organizadas em termos dos homens ganhando acesso à fertilidade feminina. Parece evidente que controlar a fertilidade, substancializada em mulheres, se apresenta como um problema. E parece evidente que mulheres substancializam fertilidade (Strathern, 1988). Essa lógica apenas demonstra a nossa própria forma de construção analítica. Ela leva apenas a uma conclusão, que é também seu pressuposto: a de que o que diferencia homens e mulheres são suas fisiologias, seus corpos. E que arranjos matrimoniais no mundo todo têm como objetivo a gestão da fertilidade feminina.

Por que imaginamos que a fertilidade feminina tem que ser controlada? Devido a algo que também imaginamos: mulheres fazem bebês (Strathern, 1988). Marylin Strathern mostra como as mulheres melanésias não fazem bebês (Strathern, 1988). Marshall Sahlins, em seu artigo "What kinship is?", mostra exemplos etnográficos, em que temos, citando o autor "homens que são mães, mulheres que são pais: não há nada de inevitável no parentesco da procriação" (Sahlins 2011:4, tradução livre). Nas mesmas linhas, Lee Drummond (apud Moore, 1988:28) argumenta que a maternidade, longe de ser a coisa mais natural do mundo, é uma das mais antinaturais: engravidar, parir, cuidar de uma criança são dilemas que necessitariam uma alta interpretação cultural.

Assim chego aos Jarawara para os quais a fertilidade está totalmente separada da parentalidade. Poderíamos dizer que nessa sociedade o parentesco está vinculado a um processo de cuidado e sedução, no qual o efeito desejado é o de "embelezar/ transformar/consertar/rejuvenescer" (namosa) as relações e o cotidiano. Como discuti alhures (Maizza, 2014), dentro dessas 
práticas do namosa enquanto transformação e sedução, se encontra o conceito de nayana, algo que poderia ser traduzido por "criação". Aproximadamente um terço das crianças jarawara são criadas por pessoas que não são seus pais biológicos. Essa "criação" ocorre não porque a criança foi abandonada pelos pais biológicos - como em alguns casos ocorre com uma criança adotada em nossa sociedade -, mas sim porque a criança foi seduzida por outros pais, que desejavam criá-la. A criança "escolhe" assim se quer ficar com seus pais ou ser criada por outras pessoas, com quem fará seus vínculos que se transformarão naquilo que pode ser chamado de parentesco, ou como diz Sahlins, na "mutualidade do ser/estar" (mutuality of being). Dizendo de outra forma: as mulheres não precisam ser férteis, engravidarem, se reproduzirem, para serem mães. O processo de reprodução aliás, é masculino: é o homem quem "faz/trabalha" (yamana) a criança no interior da barriga da mulher. Uma vez que a criança nasce, tanto o pai como a mãe devem participar de sua criação.

Se a fertilidade não parece ser algo que retém a atenção das pessoas com quem dialogo, o exercício que me proponho é tirá-la do panorama de análise. Poderia ser argumentado que toda a festa mariná, sobre a qual irei falar e sobre a qual se baseia esta etnografia, é desencadeada pela primeira menstruação da menina, $e$ por isso pelo sangue, e consequentemente pelo fato de que a jovem seria, a partir de sua menarca, fértil e apta a se casar, ter filhos. Não invalido por inteiro esse sequenciamento; é possível que ele faça algum sentido. No entanto, tudo me leva a acreditar que, na sociedade jarawara, "se casar" $e$ "ter filhos" não depende da fertilidade feminina. Vincular as mulheres às suas capacidades reprodutoras, a seus corpos, tal como nós (ocidentais) concebemos o corpo, talvez conduza a uma argumentação que, como mencionei, tem como conclusão o seu próprio pressuposto, que é a ideia de que o que diferencia homens e mulheres são seus corpos. Tal formulação se prende à nossa própria concepção daquilo que definiria "ser mulher". Opto por uma concepção que tem como referência a ideia de que "os problemas das mulheres 
não são os mesmos em todos os lugares" (Strathern, 1988:33). Se assim for, me interpelo sobre quais seriam as disposições que qualificam o feminino entre os jarawara.

\section{As sete meninas}

O mariná seria aquilo que a literatura antropológica chamou de "ritual de iniciação feminina". Existem três maneiras de fazer referência a esse tipo de evento: 1) mariná; 2) xicane, que é uma palavra do português local; 3) ayaka, sendo ayaka o nome dos cantos masculinos. Eu opto em usar o termo mariná pois ele se aproximaria mais da ideia de festa, uma festa com muita comida, um banquete. Acho que a palavra festa corresponde mais ao que vivenciam as pessoas durante esses eventos do que a palavra ritual.

Na festa mariná de Dyimamirira, que presenciei, após a última noite de danças, algumas mulheres e moças conduziram a jovem "iniciada" para o igarapé, a deram banho, perfumaram, pentearam seus cabelos e a vestiram mais uma vez com seus trajes da festa. Sete jovens meninas, que já passaram pelo mariná, se arrumaram, se pentearam, colocam batom, algumas colocaram cocares de pena (atawa); todas estavam com chocalhos feitos de conchas (kikisiri) amarrados em ambos os seus tornozelos. Ao mesmo tempo em que se arrumavam, elas fizeram uma pequena vara (awayori) com a casca de uma palmeira que retiraram das árvores em sua volta. Quando todas estavam prontas, as sete meninas fizeram uma fila indiana e Dyimamirira, ainda com seus olhos cobertos, foi posta no meio da fila, com duas meninas a sua frente e cinco atrás dela. Elas começaram a subida do igarapé para o pátio da aldeia. Algumas outras mulheres as acompanharam cantando os cantos femininos yowiri. Quando chegaram ao pátio, elas continuaram andando e cantando em fila indiana, com as varetas feitas instantes antes em suas mãos direitas.

Lá, estavam todos os convidados assistindo, e alguns meninos, aproximadamente sete, cantando os cantos masculinos 
ayaka, girando em torno de um tronco onde se fizeram todas as danças durante as três noites de festa. Ao lado do tronco estava sentado o xamã Kowisari em uma cadeira, conduzindo os cantos. As sete meninas passaram a ir e voltar em direção à roda dos homens, em um movimento de zigue e zague, cantando e dando pulos no chão para que seus chocalhos produzissem o som das conchas estalando. Elas formavam então um semicírculo, englobando a roda, e depois se afastavam novamente, em movimentos sinuosos. Elas cantavam yowiri, enquanto os homens cantavam ayaka. $\mathrm{O}$ vai e vem das moças durou alguns minutos quando, de repente, elas atacaram os meninos com suas varetas. Uma delas ficou do lado de Dyimamirira, segurando seu braço, para que ela não caísse ou se machucasse com a correria que durou um pequeno momento. Os meninos imitaram o rugido dos porcos queixadas e saíram correndo para "o mato" para escaparem dos golpes femininos. $\mathrm{O}$ clima era de brincadeira e riso, tanto das pessoas que estavam assistindo, como das que estavam participando dessa ação final.

Depois dessa sequência, a menina era presa de barriga para baixo em um tronco de árvore e era então "chicoteada" (kokosia) por alguns homens, normalmente seus afins - essa prática entrou em desuso há mais ou menos 10 anos. O chicote era uma vareta, muito parecida com aquelas que levavam as sete meninas. Os golpes eram dados no meio das costas até a pele sangrar, deixando uma pequena cicatriz para a vida toda. Hoje em dia, e já faz mais de dez anos, os pais, que decidem sobre o andamento das festas, optam por não haver "chicote" (kokosi). O argumento é que eles agora são "crentes". 4 Devido à pressão dos

${ }^{4}$ Desde a década de 1970, as aldeias jarawara têm a presença de missionários evangélicos, pertencendo à Jocum (Jovens Com Uma Missão) e ao SIL (Summer Institute of Linguistics). Em duas das três aldeias, Casa Nova e Água Branca, os religiosos possuem suas próprias casas e chegaram a residir no local durante diversos anos. Os evangélicos parecem não se opor às festas sobre as quais eu falo aqui, $e$ às vezes utilizam esses momentos para reforçar suas doutrinas. Alguns cantos se tornam cantos sobre os ensinos da bíblia, por exemplo. No entanto, eles proíbem que as meninas tenham suas costas marcadas e são contra todas as práticas xamânicas. 
missionários, após a sequência acima, ao invés da menina ser amarrada para ser chicoteada, ela é posta para sentar em uma cadeira, têm retirados o cesto/chapéu (boro) que cobria sua cabeça durante toda a festividade e a faixa que cobria seus olhos, e ouve diversos "sermões" sobre como deve ser sua conduta daqui para frente. Essas falas, feitas tanto por homens como por mulheres, por jovens como por adultos, e sobretudo pelas pessoas mais vinculadas aos pastores da Jocum, dizem, de forma geral, que ela deve trabalhar, ajudar, ouvir e obedecer sua mãe. Na festa que relato aqui, depois desses discursos, as pessoas presentes na festa, uma por uma, deram um abraço em Dyimamirira e assim terminou o mariná: "agora ela pode sair" (ewa mate amake fahi waha).

Esses eventos finais, sobretudo a subida do igarapé rumo à aldeia, a dança e o "ataque" das sete meninas poderiam ser descritos por aquilo que Houseman e Severi (2009) chamaram de "condensação ritual" - conceito que remete à teoria de cismogênese de Gregory Bateson (1936). A noção de "condensação ritual" é definida como a simultaneidade, em uma mesma sequência de ações, de modalidades de relações antitéticas (Houseman; Severi, 2009:10). Ela seria como um ápice do ritual, em que diversas relações mobilizadas durante o decorrer dele estariam "dadas a ver" ("donner à voir") e combinariam relações que em dias normais encerrariam antítese. O que se "condensa", portanto, são relações normalmente contraditórias. Para tal método de interpretação, que não me proponho aqui, seria preciso mobilizar dicotomias do pensamento jarawara, tal como baixo $\mathrm{x}$ alto, água $\mathrm{x}$ terra, homens $\mathrm{x}$ mulheres, convidados $\mathrm{x}$ anfitriões.

A sequência das sete meninas remete também às histórias que poderíamos chamar de "mitos", hiyarabote. Uma dessas histórias conta que uma mulher, mãe de uma criança de colo, queria ir para uma festa mariná dançar, e pediu para sua mãe olhar o bebê. A moça então pintou seu corpo, vestiu uma saia feita de algodão vermelho (yayafa), colocou o "rabo" (dyifori, dyifo behe) e foi participar das danças. Diversas coisas acontecem em seguida, mas eu queria apenas chamar atenção ao fato de que 
essa moça dos "tempos míticos" se veste para ficar bonita $e$ participar das danças exatamente da mesma maneira em que a jovem em reclusão é vestida durante sua festa de saída. Essa vestimenta é também a maneira como se ornam os inamati, seres celestes, "gente-planta", ideias de beleza, força e perigo (Maizza, 2012), que cantam e dançam com chocalho nos pés, em suas festas intermináveis.

Por outro lado, a pintura no corpo da menina apresenta o mesmo desenho realizado no tronco em torno dos quais são feitas as danças noturnas e também no pedaço de madeira sob o qual eram colocadas as meninas para serem chicoteadas. Foi me sugerido que esse é o desenho da pele da cobra sucurissu (makehe). Os "seres cobra" (yama maka) são muito importantes no pensamento jarawara, sendo talvez, junto com as onças (dyome), os seres mais potentes e perigosos do cosmos. Já o "rabo" (dyifori) que a menina utiliza, lembra um pedaço de tingui batido antes de ser colocado na água. É necessário primeiro bater essas raízes para que elas, uma vez colocadas dentro d'água, soltem um líquido esbranquiçado que asfixia parcialmente os peixes, fazendo com que eles nadem com dificuldade e sejam assim mais facilmente capturados/flechados. Em suma, a vestimenta e o gestual da menina nos dias de festa, e também das sete meninas, remeteria aos supra-humanos inamati, seres celestes associados ao "em cima". Enquanto a pintura da moça remeteria a seres associados com a água.

A sequência final da festa lembra também a hiyarabote (histórias antiga/"mito") de como as pessoas se tornaram queixadas (hiyama). Um dia, um homem saiu para pegar castanhas e pediu para os seus parentes esperarem. Os parentes queriam falar "como o barulho do fogo" e se transformaram (rabika) em porcos (hiyama), se dirigindo para a floresta. Quando o homem voltou, ele ficou furioso pois não haviam esperado por ele. Ele então foi atrás dos queixadas e flechou muitos deles, com flechas pequenas de zarabatana. Ele flechou inclusive a esposa dele, e a carregou, moqueou e comeu. Ele quebrou o focinho de seu filho, que voltou a ser gente. A sua irmã estava em reclusão, 
ele tirou ela do wawasa, "chicoteou" (kokosi), tirou seu "chapéu/cesto" (boro), e a "soltou" (sobana). Ele falou: "irmã, você vai virar peixe, eu também vou virar peixe". A irmã dele virou tambaqui, ele virou pirarucu, o filho dele virou pássaro. Aqui, mais uma vez, temos uma associação da moça em reclusão com a água, e uma referência ao "alto", com o pássaro.

Existiria também uma aparente relação entre queixadas e a ação para atacá-los (bater neles, flechá-los), que é sugerida igualmente nas ideais envolvendo o post-mortem. Quando uma pessoa morre, após seu enterro, diversas "almas" (kanamori) saem de seu corpo. Uma delas irá chamar seus filhos-planta, que então se juntam a ela. Como descrevi detalhadamente alhures (Maizza, 2014), para os Jarawara, as plantas que cultivam em seus roçados possuem um "duplo", uma "alma" (abono) com aparência humana, que é levada enquanto bebê à camada superior (neme) e lá é criada por um casal. No entanto, essas crianças-planta, que se tornam adultas, são filhas daquele/a que as cultivou, e, uma vez falecida essa pessoa, elas irão cuidar (kakatoma) para que sua vida post-mortem seja a mais agradável possível.

Como as pessoas plantam muito em vida, elas possuem muitos - centenas - filhos-planta, e são eles que descem à terra quando chamados, como dizia acima, e ficam à espera, ao lado do/a recém-falecido/a. Em seguida, chegam diversas pessoas com paus nas mãos (filhos-planta de outras pessoas da aldeia), e os/as enchem de pauladas, para que se tornem queixadas. A pessoa que morreu se torna o "dono" (hiti) dos queixadas, e seus filhosplanta se tornam queixadas. ${ }^{5} \mathrm{O}$ bando se dirige então para a floresta e pode ser caçado a qualquer momento. Muitas vezes, os pajés (inawa) reconhecem os queixadas caçados por algum detalhe físico da presa - um detalhe que a pessoa que se transformou naquele porco tinha em vida -, como uma mecha de cabelo mais clara, por exemplo.

Acredito haver algum tipo de associação entre "queixadas" $e$ o ato de "atacar", como sugerido nas histórias do tempo antigo

${ }^{5}$ Parece-me que apenas homens se tornam dono/cabeça ( hitt) dos queixadas. 
e na própria sequência das sete meninas. Os queixadas corporificam um tipo de presa (bani) ideal: sair para caçar é sair para caçar queixada; os outros animais (com exceção das antas, e talvez dos veados) são capturados quase como "formas de consolo". Outra qualidade que marcaria essa espécie é o fato de andarem em grupos grandes e serem sempre numerosos. Os queixadas seriam, assim, um tipo de referência de uma sociabilidade gregária bem-sucedida. Eles remeteriam a uma gente numerosa que anda junto e que anda o tempo todo. Outros seres que são também numerosos são os mencionados inamati, genteplanta, gente celeste. Os dias de festa mariná são dias em que muitas pessoas estão reunidas no mesmo local, fazendo pensar em uma possível conexão entre festa, queixada e inamati.

A minha intenção em reunir as referências apresentadas aqui é apontar para a ideia de que a festa poderia ser pensada a partir de uma análise simbólica ou estruturalista, por dicotomias, paralelismos e inversões. A sequência das sete meninas parece acionar alguns tipos de seres de grande importância na cosmopolítica jarawara: os queixadas, os "seres cobra" makehe, os xamãs, os inamati. Eles estarão em diálogo com o que me proponho a pensar agora, mas não na linha de frente, se assim posso dizer. Minha opção é de cunho fenomenológico, baseada na experiência que vivi na festa de Dyimamirira. Eu gostaria de utilizar a sequência final da festa mariná para ressaltar um único ponto: a ideia de que a menina está sendo "levada" (towaka) pelas sete meninas. O "ser levada" é a disposição em que Dyimamirira foi colocada durante todos os momentos em que saía de seu wawasa, desde o dia em que entrou nele: ela era sempre conduzida por alguém, ou tinha seu braço segurado, inclusive nos momentos de dança. O fato de estar sempre "sendo levada" está conectado ao fato de ela ter seus olhos vendados ou sua cabeça coberta, como veremos. Nos dias de festa, acredito que, mesmo 
dentro do wawasa, ela seja "levada" pelos efeitos do sono, do canto e do rapé (xinâ). ${ }^{6}$ Mas comecemos pelo início.

\section{A festa de Dyimamirira}

No dia em que Dyimamirira menstruou pela primeira vez, sua mãe Makeni e sua tia materna Hinabori, com a ajuda de dois de seus filhos, foram buscar folhas da palmeira wawasa nas proximidades da aldeia. $\mathrm{O}$ objetivo era fazer uma casinha para Dyimamirira dentro da casa familiar, onde ela ficaria até o dia da sua festa mariná. A pequena casa leva o nome da palmeira que foram procurar, wawasa. Sua mãe e sua tia passaram o dia todo trabalhando, construíram primeiro uma estrutura de galhos amarrados com "envira", em seguida cobriram esse "esqueleto" com as folhas da palmeira. Elas deixaram um espaço na lateral, colocaram um pano que funcionava como uma porta e uma pequena rede atravessada de uma ponta a outra do apertado compartimento. $\mathrm{O}$ interior do local ficou bastante escuro e quase abafado, medindo aproximadamente dois metros de comprimento por 1,5m de largura. O cabelo de Dyimamirira foi cortado, um dos seus irmãos bateu com uma vara no "teto" do wawasa, e assim começou seu período de reclusão.

Durante aproximadamente quatro meses ela permaneceu a maior parte do seu tempo sozinha dentro do wawasa, deitada na rede ou sentada em uma esteira posta embaixo dela, fazendo colares de miçanga, brincando com uma boneca, desenhando, inalando rapé (xinâ). Uma vez por dia, uma de suas irmãs a levava para tomar banho. Ela era conduzida até o igarapé seguindo seus passos ou então sendo levada pela mão. No trajeto, uma toalha era posta em sua cabeça para que, segundo me disseram, ela não visse ou fosse vista pelos homens. No fim do dia ou após o jantar, ela recebia visitas de suas amigas da mesma

${ }^{6} \mathrm{O}$ rapé (xinâ) é uma substância feita a base de folhas de xinã (tabaco), trituradas e misturadas com cinzas de casca de "cacau de terra firme" (hoko ou roco), uma fruta "parecida com o cupuaçu do mato", me disse Manira. 
idade ou um pouco mais velhas. A maior preocupação de sua "mãe" (ami) e "tias" (amise) durante o dia, pelo que eu pude perceber, era saber se Dyimamirira tinha se alimentado. A ela eram servidas diversas refeições, com farinha, peixe, arroz, feijão, uma verdadeira fartura alimentar lhe foi proporcionada. Presenciei o início da reclusão de Dyimamirira, e quando voltei meses depois para sua festa, percebi que ela tinha engordado. Minhas amigas inclusive me perguntaram sobre esse aspecto, indagando se eu havia visto como ela estava "gordinha" em português, ou simplesmente "bonita" (amosake) em jarawara.

Ao contrário do que se pode imaginar, passar dias e mais dias dentro do wawasa traz diversas disposições, mas relaxar ou descansar não fazem parte delas. No decorrer do dia, o calor e a falta de luz fazem com que o interior da casinha seja um lugar um tanto abafado e um tanto solitário. Dyimamirira chamava por sua mãe $e$ irmãs diversas vezes ao dia. Às vezes para ir ao banheiro, às vezes para pedir alguma coisa, como água, às vezes para manifestar um desconforto. Sempre era preciso que alguém ficasse nas proximidades do wawasa para "cuidar" (kakatoma) de Dyimamirira. Se sua mãe desejasse passar a manhã no roçado por exemplo, pedia para uma de suas filhas ou uma de suas irmãs para que permanecesse nas proximidades da casinha. À noite, tudo se tornava ainda mais tenso. Mais de uma vez, Makeni (a mãe de Dyimamirira) comentou comigo que estava muito cansada, que havia dormido mal porque Dyimamirira tinha chamado muito ela, tinha chorado de madrugada dizendo que estava com medo, medo de inamati, que estava com calor, que não estava bem. Makeni, dormia em uma rede amarrada junto a rede de seu esposo, pai de Dyimamirira, e era comum ter que acordá-lo para ele dormir em outro lugar, para que sua filha viesse dormir com ela e elas pudessem enfim descansar. ${ }^{7}$ A experiência vivida dentro do wawasa me foi descrita pelas jovens que recentemente passaram por ela como uma experiência de medo $e$

\footnotetext{
7 Os homens, mesmo o pai da menina, não podem vê-la durante todo seu período de reclusão.
} 
ansiedade. Quanto mais a festa se aproxima, mais essas sensações aumentam. As moças ficam muito preocupadas (aawawa na) com o que vai acontecer com elas durante o mariná. Na noite antes da sua festa, Dyimamirira não conseguiu dormir, "estava louca" (rabika) segundo seu pai, e ficou conversando muito com sua mãe. No final, ela teve que dormir, mais uma vez, na rede com Makeni.

Kamo (o pai de Dyimamirira) havia decidido uma data para "soltar" (sobana) sua filha, quatro luas cheias depois de sua entrada no wawasa. Eu retornei à Casa Nova especialmente para a ocasião. Perto da data marcada, o irmão de Dyimamirira programou um campeonato de futebol. O dia exato do início da festa parecia ser dificilmente comunicável, havendo, segundo me explicaram, algumas coisas a serem feitas antes dele. A primeira era o campeonato (um dia inteiro), e a segunda era esperar dois a três dias após seu término para que os homens, anfitrióes $e$ convidados, saíssem para caçar e fizessem um aprovisionamento de carne de caça (bani). E assim foi. A cena que descrevi para abrir este artigo ocorreu justamente no final do dia de campeonato. Na manhã seguinte, após a noite de forró, os convidados e convidadas yara ("brancos") foram embora. Alguns homens da aldeia vizinha, Saubinha, ficaram para caçar $e$ permaneceram até o dia da festa. Outros, sobretudo os jovens pais de família, voltaram para casa para retornar à Casa Nova três dias mais tarde.

A festa começou no quarto dia depois do campeonato, quando por volta das nove da manhã um irmão mais novo (ayo) de Dyimamirira bateu com uma vara no teto do wawasa saindo em seguida do local, e diversas mulheres sentaram-se ao lado da casinha e começaram a entoar os cantos eé. Esses são cantos que os pajés ouviram das mulheres do neme ("camada superior") em suas diversas visitas e "trouxeram" (kakıl) para ensinar às suas esposas e filhas - suas verdadeiras conhecedoras. Cada um deles fala sobre uma espécie animal descrevendo, por assim dizer, uma 
característica ou ação específica. ${ }^{8} \mathrm{O}$ refrão das canções, que creio eu, dá nome a elas (eê), é sempre o mesmo: "E hinari, eé hinari", que poderia ser traduzido como "é o que contaram, o que foi dito". São cantos agudos e envolventes, que devido à repetição constante do refrão e à altura da nota, dão a impressão de serem um único e infinito canto. As mulheres que lá estavam quando o mariná de Dyimamirira começou, cantaram o dia inteiro, sem interrupção, não ouve um só momento até as $17 \mathrm{~h}$ em que o ambiente ficou em silêncio. Dyimamirira ouvia de sua rede, os cantos eram entoados para ela. Algumas cantoras iam e voltavam, outras ficaram só de manhã, outras chegaram depois do almoço, mas muitas passaram o dia sentadas, conduzindo ou seguindo os cantos. Enquanto cantavam, sentadas, algumas cuidavam de seus filhos pequenos, outras faziam colares, outras pintavam suas unhas, e aquelas mais próximas de Dyimamirira finalizavam detalhes da vestimenta que ela colocaria naquela noite $-e$ nas outras duas noites de danças. Parece-me que os cantos eé são importantes para que a menina seja "levada" para outros temposespaços e encontre com os inamati, "seres celestes" - voltarei a esse ponto mais adiante. É possível também que os cantos eé descrevam os diferentes seres com quem a moça se encontra no decorrer de suas viagens.

No final do dia, os cantos eé cessaram, as pessoas foram tomar banho e se arrumar para o jantar que começou no início da noite. Kamo e Makeni, os pais da menina, haviam estocado farinha durante meses, comprado arroz e macarrão; os homens que haviam saído para caçar tinham trazido macacos, porcos do mato e pássaros. O jantar foi farto, todos os convidados, em torno de cem pessoas, receberam um prato cheio e um copo de refrigerante. Após o jantar, houve um momento de descanso mas não para Dyimamirira que recebia visitas em seu wawasa, $e$ inalava rapé com suas amigas durante esse tempo. E por volta das onze da noite, a "mãe" (ami), "tias" (amise), "irmãs" (ati/ asima)

8 Por exemplo: "O jupará (bani hoso) vem de noite procurar comida, ele acha, ele conversa muito: "hosohoso". Então outros (juparás) vêm (também) comer". 
começaram a arrumá-la para os cantos e danças noturnas. Primeiro, foi colocada sua saia de algodão tingida com urucum (yayafa), em seguida colocaram um cinto com dois detalhes de pena, um de cada lado; então os chocalhos de conchas (kikisiri) em ambos seus tornozelos, um "rabo" (dyifori) feito de folha de buriti (dyifo) e com a ponta tingida de urucum; e por último, cobriram seus olhos com uma faixa de pano e, em seguida, colocaram um cesto (boro) em sua cabeça, ornamentado com quatro penas de arara vermelha, uma em cada extremidade, direcionadas para cima. ${ }^{9}$ Acho que, nesse momento, ela deveria ter sido pintada, o que neste mariná, em específico, não ocorreu, pois não havia jenipapo para fazer a pintura em preto (a pintura é feita com urucum, vermelho, e jenipapo, preto).

Nessa primeira noite, que era, lembremos, o primeiro dia de saída de Dyimamirira após meses de reclusão, as mulheres próximas, e eu mesma, estavam muito animadas, preparadas para fazer uma noite de dança bonita. Alguns minutos antes, homens convidados haviam chegado escondidos, de repente, na casa onde a grande maioria das pessoas estava reunida esperando, $e$ deram "pancadas" no teto - o que fez todos levantarem e imitarem, com muitos risos, macacos barrigudos (wafa), deixando a atmosfera elétrica. Mas quando ela saiu, enfim, da casa, desceu as escadas ${ }^{10}$ e chegou no pátio onde seriam as danças, ela começou a se sentir mal. Ela não conseguia ficar de pé e dizia baixinho estar muito cansada, quase com dificuldade de respirar. Colocaram então uma cadeira para que ela se sentasse, e durante algum tempo ela se levantava e se sentava novamente na cadeira, exausta com seus poucos movimentos. Eu fiquei bastante preocupada e achei que a festa não continuaria, mas minha amiga Hinabori, que estava ao meu lado observando, me disse que aquilo era muito normal, "Dyimamirira estava cansada".

9 Wero me disse que Dyimamirira estava "carregando" (weye) as penas, o boro e a saia, indicando que o "carregar" pode ser usado também para o que nós chamamos de vestir.

${ }^{10}$ Todas as casas são altas, em estilo palafita. 
Como disse antes, o período de isolamento da menina não é em nada calmo e nem um período de repouso. Ao meu ver, esse primeiro momento em que vemos Dyimamirira "em cena" por assim dizer, mostra o quão exausta ela estava antes mesmo de se iniciar a festa. Os meses dentro de seu wawasa escuro, marcados por dias solitários, medos, ansiedades, desconfortos e noites mal dormidas, podem, como me parece ter sido, fazer de sua primeira saída uma "explosão sensorial". Seu corpo está diferente, agora com mais curvas e gordura, mais pesado. O boro e a faixa que cobrem seus olhos estimulam, ao meu ver, sensações outras que a visão. Era como se Dyimamirira estivesse experimentado repentinamente, de uma só vez, os efeitos dos meses de isolamento, e ao longo da festa, esses efeitos iriam se tornar cada vez mais fortes e presentes.

Algumas mulheres deram então início às danças $e$ aos cantos femininos, yowiri, e a roda foi ficando cada vez mais cheia. Dyimamirira foi posta no meio da ciranda para dançar. Durante as primeiras horas, ela teve que sentar diversas vezes, ainda por conta do seu cansaço, mas do meio da madrugada em diante, ela não parou mais de rodar. Ela dançou a noite inteira - sempre sendo levada/segurada por duas pessoas, uma de cada lado -, girando de um lado e depois de outro, ouvindo, mas jamais cantando, os cantos femininos yowiri, e pulando de tempos em tempo com força no chão, para que seus chocalhos produzissem o som das conchas. Quando amanheceu, ela foi levada por suas "irmãs" para o igarapé, retirou-se o seu boro, foi lhe dado banho, foi colocado de novo seu boro e sua vestimenta, e ela foi levada de volta para seu wawasa. Imagino que ela estivesse exausta, mas mal ela entrou e deitou em sua rede, diversas mulheres (não as mesmas que passaram a noite dançando) chegaram, sentaram $e$ começaram os cantos eé.

E assim foi o dia todo, preenchido por cantos eé, depois jantar, visitas, vestimenta, e danças noturnas, agora com cantos masculinos (ayaka). Ao amanhecer: banho, e de volta para o wawasa, e depois eé, jantar, visitas e danças, agora com o xamã Kowisari liderando os cantos ayaka. Assim se passaram três dias e 
três noites. Eu me propus a gravar os cantos do mariná, e procurei acompanhar Dyimamirira o tempo todo. Como disse no início, sua mãe havia me dado um bom lugar para ficar, a poucos metros do wawasa de sua filha, o que me proporcionou uma agradável proximidade. $\mathrm{O}$ que posso dizer é que eu quase não dormi, a não ser nos inícios de noite antes das danças - enquanto ela recebia visitas em seu wawasa. Eu fiquei completamente atordoada de sono, o que parecia ser bastante gratificante para as pessoas que me viam, pois diversas vezes me foi perguntado se eu estava com sono, quase como se validando minha vivência do mariná. Se eu quase não dormi, Dyimamirira não deve ter dormido nada, ou melhor, não lhe foi proporcionado um só momento em que pudesse dormir; havia sempre alguém cantando ao seu lado, ou então ela estava acompanhada inalando rapé ou no meio de uma roda de danças. ${ }^{11}$

As açóes do mariná parecem configurar uma situação em que a menina dorme pouco. Tudo indica que Dyimamirira experimentou durante a festa um estado de sonolência constante, consequente de sua falta de sono. Como se a falta de sono (prolongada) fizesse com que ela pudesse sonhar a qualquer momento. Como se ela se encontrasse em um estado de sonolência (nokobisa) e cansaço (amaha) que a levariam para uma disposição onírica. O sono funcionaria quase como um $e^{\text {entorpecente }}{ }^{12}$ que a faria "sonhar" e a deixaria "leve". Leve não como antônimo de pesada, mas sim como "levável", possibilitador

\footnotetext{
${ }^{11}$ Ela é a única a vivenciar a festa desta maneira, as outras pessoas participam de algum momento (ou do eé, ou da dança noturna, ou fazem uma visita) mas não de todos.

${ }^{12}$ Para Anne-Christine Taylor os rituais de iniciação nas Terras Baixas se baseiam na submissão à uma experiência de transformação corporal provocada ou pela dor, ou pela ingestão de psicotrópicos ou por alguma outra forma de modular a sensação de seu corpo e de seu ambiente (Taylor, 2010:42). As operações "na carne" trabalhariam o corpo para modificar a consciência - através de experiência corpóreas inabituais - enquanto os psicotrópicos alterariam a percepção do corpo, permitindo a experiência de um corpo "outro" (Viveiros de Castro; Taylor, 2006:195). Parece-me que a sonolência assim como praticada nas festas mariná, seria análoga à ingestão de um psicotrópico.
} 
do "ser levada" (towakama), "ser carregada" (weyena), "ser trazida/conduzida" (kaki). São essas as ideias que me guiarão nesta parte final.

\section{Que se leve}

Em minhas estadias em Casa Nova, as pessoas me explicaram que a alma (abono, kanamori) pode se desvencilhar do corpo e viver experiências com outros tipos de seres..$^{13}$ Essas experiências são perigosas e indesejadas pois indicam um estado fora de controle, que pode levar até a morte. Estar doente é um desses estados em que a alma (abono) foi capturada/ segurada/roubada por outros tipos de seres e lá está, com eles, em suas aldeias, no mesmo momento em que o corpo padece. É preciso ir buscar, trazer (kaki) e colocar a alma de volta dentro do corpo - quem faz isso são os filhos-planta do xamã, convocados por ele. Contaram-me uma história em que duas almas mulheres (duas almas de macaco fêmea), capturaram a alma de um homem quando ele estava caçando sozinho na floresta e a seguraram, amarraram-na com envira, e queriam se casar com ele. $\mathrm{O}$ homem ficou muito doente, mas no final foi curado pelo pajé Kanabono. Entendi o pavor que a ideia de tal evento pode causar quando vi uma foto que estava circulando por Lábrea, a cidade mais próxima, de que jovens jarawara tinham cópia em seus celulares. Era a foto de um homem pequeno, com os membros atrofiados, com a pele fina e rosada, careca. Ele foi achado por dois caçadores de Lábrea (um deles tirou a foto) montando em um queixada e "comandando/ conduzindo" um grupo desses porcos do mato. Um caçador matou o homem e morreu algumas horas

\footnotetext{
${ }^{13}$ A grande questão existencial para boa parte das sociedades indígenas é que a alma é destacável, por assim dizer, do corpo, e isso dá instabilidade para o corpo. Esta instabilidade se deve ao fato que possuir uma alma implica na capacidade de poder se transformar, virar um outro tipo de pessoa, um outro tipo de gente, mudar de perspectiva (Lima, 1996; Viveiros de Castro, 1996). Por isto, saber controlar as possíveis metamorfoses corporais é essencial para que as pessoas vivam bem nestas sociedades.
} 
depois. O outro enlouqueceu. As pessoas de Casa Nova identificaram aquele ser como "o dono (hiti) dos queixadas" que mencionei antes. A foto me apavorou. Compreendi a dimensão do problema de ter a alma capturada e viver com aquela criatura da imagem, por exemplo.

O sonhar é uma experiência similar ao adoecer. Okomobi me disse que "quando a gente dorme, o corpo fica na rede, mas a alma vai ao 'céu' (neme), passear, fica lá conversando". Em muitos momentos quando estava em Casa Nova, no início da manhã, em volta do fogo que aquece quem sai da rede, $e$ onde as pessoas ficam alguns instantes assim que levantam, alguém me falava que tinha "sonhado com alma" (inamati, yawita abono, dyafari abono...). A conversa era muito curta, apenas uma indicação daquele infeliz incidente, que deixava a pessoa sempre muito preocupada. Uma vez, um senhor me contou que teve um sono turbulento: ele sonhou que estava todo enrolado com uma linha - como linha de malhadeira (rede de pesca). Um inamati tinha o enrolado, prendido, e o colocado de cabeça para baixo. Quando ele acordou, viu que sua rede de dormir estava apertando ele. Como se a vida aqui e a vida nos sonhos (a vida das almas, dos inamati) fossem mundos paralelos que podem se alinhar em certos momentos; a experiência onírica sendo uma forma poderosa para esse tipo de passagem, de uma realidade à outra, de uma perspectiva à outra (Lima, 1996).

$\mathrm{Na}$ língua jarawara, o estado involuntário em que a alma se desprende do corpo é chamado labirika ou rabika, traduzido em português por "ficar doido". Já ouvi o termo labirika sendo usado em caso de doença, febre (malária), bebedeira, grande ansiedade, namoros escondidos e outras situações. O conceito é também mobilizado nas narrativas dos tempos antigos, nos mitos (hiyarabote), indicando o momento em que um tipo de gente sofreu metamorfose (para sempre) para uma espécie animal. Nunca ouvi esse termo ser usado para o pajé, que é aquele que deve vivenciar encontros com outros tipos de seres. Seu conhecimento sobre o mundo - os mundos - é tecido durante suas viagens através do que ele vê quando inala rapé e é 
"carregado" (weye) nas costas de seus filhos-planta, chegando em aldeias distantes e conhecendo as pessoas/seres que lá habitam. Nos ayaka (cantos) de um pajé ouvimos suas histórias, como um dia ele chegou em uma aldeia no neme, e estava todo mundo cantando, dançando, fazendo mariná. Ou então, como em outra aldeia "lá em cima" (nemeya), ele foi perseguido por uma onça.

Davi Kopenawa, no livro escrito com Bruce Albert, A queda do céu, fala de sua experiência enquanto xamã. Essa experiência está vinculada ao viajar e conhecer o mundo dos xapiri - almas, espectros, seres celestes, que corresponderiam aos inamati jarawara - lindos, brilhantes, o ideal de beleza e da humanidade. Ele fala que para fazer essas viagens, ele mesmo deve "se tornar espectro", "se tornar xapiri" (Kopenawa; Albert, 2010:368), por dois meios: ingestão nasal da substância alucinógena chamada yãkoana e o sonho (Kopenawa; Albert, 2010:52). Se essas são as formas privilegiadas para se "tornar espectro", ao longo do livro, Davi indica também outras maneiras, mais involuntárias, em que isso pode acontecer a qualquer pessoa, não apenas aos xamãs. Elas são: bebendo o mingau de banana na festa reahu (Kopenawa; Albert, 2010:211); bebendo cachaça (Kopenawa; Albert, 2010:353); quando se está doente, com febre (Kopenawa; Albert, 2010:177, 269, 381); quando se come comida desconhecida como a comida dos brancos (Kopenawa; Albert, 2010:421); quando uma pessoa fica com muita dor ou raiva (Kopenawa; Albert, 2010:473); e sonhando. Todo mundo ao sonhar tem acesso ao mundo dos xapiri, mas as pessoas comuns (não xamãs), não viajam muito longe (Kopenawa; Albert, 2010:498).

Nessas circunstancias (essa lista não é exaustiva), teríamos aquilo que os antropólogos chamam de separação entre alma e corpo, e que Davi chama de "se tornar espectro". A experiência que a alma vivencia é a experiência de "viajar". Essa "viagem", como fala Kopenawa, é também vinculada a outros temposespaços. Ele conta que. às vezes, quando ele "se torna espectro", vê eventos daquilo que nós, antropólogos, chamaríamos de mito. Por exemplo, o dia em que vivenciou o tempo em que seus ancestrais viraram animais (Kopenawa; Albert, 2010:99). Para Davi, 
sonhar, se tornar espectro, é a forma de conhecimento por excelência. "Nós, yanonami, quando queremos saber coisas, fazemos um esforço de vê-las sonhando" (Kopenawa; Albert 2010:502, tradução livre, grifos no original). Nesse aprendizado, os xapiri, os seres celestes, almas, espectros, são os professores. "Essa é nossa forma de se tornar sábio, nós, as pessoas da floresta, nunca esquecemos os lugares que visitamos em nossos sonhos" (Kopenawa; Albert, 2010:502, tradução livre).

Voltando ao mariná. Parece-me que o efeito dos dias do mariná é incentivar a menina a sonhar. O estado de cansaço em que ela é conduzida durante sua reclusão se transforma, no decorrer da festa, em uma disposição de profunda sonolência (nokobisa), que se tornaria um estado de experiência onírica. Ela estaria muito cansada, com muito sono, e por isso "leve" (no sentido de "levável"). Essa disposição a possibilitaria "ir", "ser levada", encontrar seres de outros tempos-espaços, viver experiências, adquirir conhecimentos sobre o mundo, os mundos, encontrar com os inamati em suas casas 'lá em cima', aprender com eles. Os elementos que possibilitariam esse agenciamento levável seriam: o sono, os cantos eé e o rapé. Marylin Strathern conta que em Hagen, os ritos construiriam maneiras de saber quais são as capacidades do corpo (Strathern, 1988:103), e as evidências dessas capacidades repousam na eficácia da ação, que implica, na Melanésia, em relação (Strathern, 1988:123). O efeito desejado dos "rituais de iniciação masculina" em Hagen é trazer consciência para o corpo e, no idioma melanésio, mostrar o impacto das mentes das pessoas sobre outras (Strathern, 1988:131). Se pensarmos na festa de Dyimamirira, em sua disposição onírica, podemos arriscar a dizer que o mariná procura trazer consciência para a alma, mostrar as capacidades da alma, mostrar que as almas podem ser levadas (towaka), trazidas (kaki), carregadas (weye), seguradas (tama), e que esses deslocamentos são importantes formas de conhecimento. Acredito que o "ser levável", "carregável", é uma qualidade possivelmente vinculada à agência feminina. Qualidade que seria revelada às mulheres durante o mariná. 
Ao mesmo tempo, durante os dias de festa, Dyimamirira experimentava um corpo mais pesado, engordado. As danças noturnas em que ela pulava com vitalidade para fazer soar seus kikisiri (chocalhos de tornozelo), faziam sentir a força de seu peso no chão. Um corpo que é agora bonito - uma mulher bonita é uma mulher encorpada - e que durante o mariná está ainda mais belo, pois pintado, ornado, enfeitado, vestido formosamente. Além disso, a atmosfera é de muita beleza devido aos cantos e danças, e também à alegria e à animação dos convidados $e$ anfitriões. Enfim, me parece que a ideia de um corpo pesado não seria incompatível com o conceito de "ser levável". Os xamãs (inawa) são viajantes que se deslocam "carregados" nas costas (weye) de seres celestes (seus filhos-planta). Desses xamãs diz-se terem diversas "pedras" (arabani, yama nakora) inseridas ao longo da vida em seus corpos. Essas "pedras", que são também meios de feitiços (Maizza, 2012), são como pequenos pedaços de ouro, brilhantes e densas, o que poderia indicar uma certa noção de peso nos corpos dos pajés.

Outros seres "carregáveis" no mundo jarawara - para os quais se usa igualmente os termos weye, towaka, kaki, tamaka são as crianças, que são transportadas em tipoias até pelo menos quatro anos de idade em momentos de caminhadas; algumas espécies de plantas cultivadas, que são levadas de lugares próximos das casas onde são plantadas para os roçados quando crescem e já estão maiores; as presas, que são capturadas na floresta e carregadas mortas até as casas; as pessoas doentes que devem ser levadas até a cidade; as almas (kanamori) dos mortos, que são carregadas por seus filhos-planta até a camada superior (neme). Em todos os casos, não parece haver uma contradição entre "ser/estar pesado/a" e "ser levável". No caso da menina em reclusão e dos pajés, acredito que a utilização do rapé seja importante no levar, mas não poderei desenvolver esse ponto com mais profundidade aqui. 
Em nossa maneira de conceber os problemas com o qual nos propomos a lidar na Antropologia, temos tendência a sobrepor categorias analíticas (Strathern, 1980), e acabamos fazendo encadeamentos de pressupostos. Muitas vezes, essas cadeias fazem sentido apenas para nós e não para as pessoas com quem trabalhamos, e passam despercebidas - tanto para aquele/a que as formula como para seus/suas leitores/as. Um bom exemplo desse tipo de procedimento é a oposição: mulher/natureza/ doméstico versus homem/cultura/público, sobre a qual falei no início deste artigo. No caso do mariná e seus efeitos, eu teria a tendência a sobrepor as categorias: mulher, corpo pesado, presa. Apesar do intenso debate sobre a dicotomia natureza e cultura nos estudos consagrados às Terras Baixas, pouco se discutiu sobre as questóes levantadas pela antropologia feminista - com exceção de autoras como, por exemplo, Vanessa Lea, Cecilia McCallum e Bruna Franchetto. Um dos motivos disso, talvez tenha sido o fato de os/as etnólogos/as se concentrarem nas complexas relações interespécies, argumentando que a distinção de gêneros seria, nas sociedades indígenas, eclipsada pela divisão "humanos versus não humanos" ou então pela divisão entre "presa e predadores" (Descola, 2001, Vilaça, 2005; Taylor; Viveiros de Castro, 2006). E assim, as mulheres foram por vezes qualificadas nas etnografias como "presas" (Taylor, 2000).

Eu mesma pensei em um primeiro momento que a reclusão $e$ a festa das meninas jarawara poderia ser uma forma de transformá-las em "mulheres-queixada". Mas depois de participar da festa de Dyimamirira, e me abrir para outras possibilidades de entendimento, venho refletindo sobre a ideia de que o mariná não coloca as mulheres em posição de presas, mas sim que a reclusão $e$ as festa revelam o fato de as mulheres terem algumas qualidades análogas às qualidades das presas, como "ter peso" e poder "ser levada". Isso não faria das mulheres presas, e muito menos presas dos homens: acredito que essa formulação possivelmente tende a demonstrar um ideal nosso, já mencionado, de achar que existe uma submissão da natureza pela cultura que pode ser vista na submissão universal feminina. As qualidades acima não são 
exclusivas às presas; elas são também atribuídas a outros sujeitos, dentre eles, os xamãs. Elas apontam para uma forma de agência que habilitaria as mulheres a viajar, a sair, a adquirir conhecimento através de seus sonhos. Elas aproximariam as mulheres dos conhecimentos xamânicos e das complicadas redes de relações cosmopolíticas em que os pajés se inserem. Enfim, doméstico e mulher talvez não sejam categorias que se sobrepõem, pelo menos não entre os jarawara. ${ }^{14} \mathrm{~A}$ agência feminina "levável" (towaka), "carregável" (weye) projeta as mulheres mais para um possível "fora" do que para um possível "dentro".

\section{Referências bibliográficas}

BAteson, Gregory. Naven: A Survey of the Problems suggested by a Composite Picture of the Culture of a New Guinea Tribe drawn from Three Points of View. Stanford University Press, 1958 [1936].

BRAH, Avtar. Diferença, diversidade, diferenciação. cadernos pagu (26), Campinas-SP, Núcleo de Estudos de Gênero-Pagu/Unicamp, 2006, pp.329-376.

COLliER, Jane; YANAGISAKO, Sylvia. Introduction. In: COlliER, Jane; YANAGISAKO, Sylvia (eds). Gender and Kinship. Essays toward a Unified Analysis. Standford, Standford University Press, 1987, pp.113.

COLLIER, Jane; YANAGISAKO, Sylvia. Toward a Unified analysis of gender and kinship. In: COLlier, Jane; YANAGISAKO, Sylvia (eds). Gender and Kinship. Essays toward a Unified Analysis. Standford, Standford University Press, 1987, pp.14-50.

DAVIS, Angela. Mulheres, raça e classe. São Paulo, Boitempo, 2016.

DESCOLA, Philippe. The genres of gender: local models and global paradigms in the comparaison of Amazonia and Melanesia. In: GREGOR, Thomas; Tuzin, Donald (eds.). Gender in Amazonia and Melanesia. Berkeley, University of California Press, 2001, pp.91-114.

\footnotetext{
${ }^{14}$ Ver Lea (2000) para uma opinião similar sobre as mulheres Mebengôkre.
} 
FRANCHETTO, Bruna. Apresentação do Dossiê Mulheres Indígenas. Revista Estudos Feministas, vol. 7, n 1 e 2, UFSC, 2000, pp.141142.

FRANCHETTO, Bruna; MONTAGNANI, Tommaso. Flûtes des hommes, chants des femmes. Images et relation sonores chez les Kuikuro du Haut-Xingu. Gradhiva. Revue d'anthropologie et de histoire des arts, 2011, vol. 13, pp.94-111.

HARAWAY, Donna. A Cyborg manifesto. Science, technology and socialist-feminist in the late twentieth century. Socialist Review 80, 1985, pp.65-107.

- Gênero para um dicionário marxista: a política sexual de uma palavra. cadernos pagu (22), Campinas-SP, Núcleo de Estudos de Gênero-Pagu/Unicamp, 2004, pp.201-246

HousemAN, Michael; SEVERI, Carlo. Naven ou le donner à voir. Essai d'interprétations de l'action rituelle, Paris, CNRS-Éditions, Éditions de la Maison des sciences de l'homme, 2009.

KoPenAWA, Davi; AlBERT, Bruce. La chute du ciel: paroles d'un chaman yanomami. Paris, Terre Humain/ Plon, 2010.

LATOUR, Bruno. Jamais fomos modernos: ensaio de antropologia simétrica. Rio de Janeiro, Editora 34, 2001 [1991].

LEA, Vanessa. Desnaturalizando gênero na sociedade Mẽbengôkre. Revista Estudos Feministas, vol. 7, n 1 e 2, UFSC, 2000, pp.176194.

- Riquezas intangíveis de pessoas partíveis: os Mebêngôkre (Kayapó) do Brasil Central. São Paulo, Edusp, 2012.

LIMA, Tania Stolze. O dois e seu múltiplo: reflexões sobre o perspectivismo em uma cosmologia tupi. Mana 2(2), 1996, pp.21-47.

LORDE, Audre. The master's tools will never dismantle the master's house. In: MORAGA, Cherrie; ANZALDUA, Gloria (eds). This bridge called my back. Writing by radical women of color. Watertown, Massachusetts, Persephone Press, 2015, pp.94-97 [1981].

MACCORMACK, Carol. Nature, culture and gender: a critique. In: STRATHERN, Marylin; MACCORMACK, Carol (eds). Nature, Culture and Gender. Cambridge, Cambridge University Press, 1980. 
MAHMOOD, Saba. Feminist theory, embodiement, and the docile agent: some reflections on the Egyptian Islamic revival. Cultural Anthropology, vol.16, n 2, 2001, pp.202-236.

. Politics of piety. The islamic revival and the feminist subject. New Jersey, Princeton University Press, 2005.

MAIzZA, Fabiana. Cosmografia de um mundo perigoso. Espaço e relaçóes de afinidade entre os Jarawara da Amazônia. São Paulo, Edusp/ Nankin editorial, 2012.

- Sobre as crianças-planta: o cuidar e o seduzir no parentesco jarawara. Mana 20 (3), 2014, pp.491-518.

MCCAllum, Cecilia. Gender and Sociality in Amazonia: How Real People Are Made. Oxford, Berg, 2001.

. Becoming a Real Woman: Alterity and the Embodiment of Cashinahua Gendered Identity. Tipiti: Journal of the Society for the Anthropology of Lowland South America, vol. 7, n 1, Article 2, 2009.

MOHANTY, Chandra Talpade. Under Western Eyes: Feminist Scholarship and Colonial Discourse. Boundary 2, vol. 12, $\mathrm{n}^{\circ} 3$, On Humanism and the University I: The discourse of Humanism, 1984, pp.333-358.

Moore, Henrietta. Feminism and Anthropology. Cambridge, Polity Press, 1988.

. Understanding sex and gender. In: Ingold, Tim (ed.). Companion Encyclopedia of Anthropology. Routledge, 1994, pp.813-830.

ORTNER, Sherry. Is Female to Male as Nature is to Culture? In: ROSALDO, Michelle; LAMPHERE, Louise (eds.). Women, Culture and Society. Standford University Press, 1974, pp.67-87.

ROSALDO, Michelle. Women, culture and society: a theoretical overview. In: ROSALDO, Michelle; LAMPHERE, Louise (eds.). Women, Culture and Society. Standford University Press, 1974, pp.17-43.

SAHLINS, Marshall. What kinship is (part one). The Journal of the Royal Anthropological Institute (NS), 17, 2011, pp.2-19

. What kinship is (part two). The Journal of the Royal Anthropological Institute (NS), 17, 2011, pp.227-42. 
STRATHERN, Marilyn. No nature, no culture: the Hagen case. In: STRATHERN, Marylin; MACCORMACK, Carol (eds). Nature, Culture and Gender. Cambridge University Press, 1980, pp.174-222.

. The Gender of the Gift. University of California Press, 1988.

. Feminist critique. In: STRATHERN, Marilyn. Partial Connections. Altamira Press, 2004, pp.29-40 [1991].

- O efeito etnográfico. In: STRATHERn, Marilyn, $O$ efeito etnográfico e outros ensaios. São Paulo, Cosacnaify, 2014, pp.345406.

TAYLOR, Anne-Christine. Le sexe de la proie: représentations jivaro du lien de parenté. L'Homme 154-155, 2000, pp.309-334.

. Voir comme un Autre: figurations amazoniennes de l'âme et des corps. In: DESCOLA, Philippe (dir.). La Fabrique de images. Visions du monde et formes de la representation. Paris, Musée du quai Branly/Somogy, 2010, pp.41-51.

TAYLOR, Anne-Christine; VIVEIROS DE CASTRO, Eduardo. Un corps fait de regards. In: BRETON Stéphane et alii (orgs.). Qu'est-ce qu'un corps? (Afrique de l'Ouest/ Europe occidentale/ Nouvelle-Guinée) Amazonie). Paris, Musée du Quai Branly/Flammarion, 2006, pp.148199.

TRINH, T. Minh-ha. Difference: "a Special Third World Women Issue". Feminist Review, n² 25, 1987, pp.5-22.

VILAÇA, Aparecida. Chronically unstable bodies. Reflexions on Amazonian corporalities. The Journal of the Royal Anthropological Institute 11 (3), 2005, pp.445-464.

VIVEIROS DE CASTRO, Eduardo. Os pronomes cosmológicos e o perspectivismo ameríndio. Mana 2(2), 1996, pp.115-144. 